\title{
Categorizando el patrimonio salvadoreño. Una breve aproximación*
}

Categorizing the salvadorean heritage. A brief approximation*

\author{
Sofía Albayero \\ Arqueóloga \\ sofiaalbayero@gmail.com
}

http://hdl.handle.net/11298/410

Recibido: 21/07/17 - Aceptado: 20/10/17

( Este texto fue elaborado como documento base para el desarrollo del seminario "Un vistazo a nuestro patrimonio cultural", dictado por la autora a estudiantes de la asignatura de Realidad Nacional en el ciclo 1/2017, el día 25 de febrero de 2017 en las instalaciones de la Universidad Tecnológica de El Salvador.)

$\left({ }^{\star}\right.$ This text was prepared as a base document for the development of the seminar "A look at our cultural heritage," as presented by the author to the students in the subject course of National Reality during the Spring Semester- 2017. The lecture took place on February 25, 2017, at the campus of Universidad Tecnológica de El Salvador.)

\section{Resumen}

El presente documento muestra una aproximación teórica de la categorización del patrimonio salvadoreño en sus dos vertientes: natural y cultural; y dentro de estas están los tipos de patrimonio inmaterial o intangible, y material o tangible. En cuanto a este último, incluye los subtipos de inmueble y mueble, con sus correspondientes categorías. El patrimonio salvadoreño es el testimonio de la cultura, se dimensiona en la globalidad del territorio y en las diferentes manifestacion que evoca el patrimonio, para configurar el sentido de pertenencia y las identidades de los habitantes de El Salvador.

\section{Palabras clave}

Patrimonio cultural - El Salvador; Identidad cultural - El Salvador; Historia-El Salvador; Historia natural -El Salvador

\section{Introducción}

"El patrimonio no es solamente sede de la memoria de la cultura de ayer, sino también el laboratorio donde se inventa el mañana" (Koichiro Matsuura, ${ }^{2}$ en Velasco Quintana, 2016).

En este texto, se procura establecer y aplicar conocimientos teóricos en relación con las diferentes categorías,

\section{Abstract}

This document introduces a theoretical approximation to the classification of the Salvadorean heritage in its two lines: natural and cultural. Within them, two types can be found: intangible heritage, and tangible material, respectively. In regards to the latter, this includes the subcategories of movable and inmovable properties, with its corresponding categories. The Salvadorean heritage is the testimony of its culture; without its full development, as reflected in the totality of the miterritory, one cannot totally evoque the sense of belonging and the identities of those living in El Salvador.

\section{Keywords}

Cultural Heritage - El Salvador; Cultural identity - El Salvador; History - El Salvador; Natural history - El Salvador

importancia del patrimonio cultural de El Salvador y su representación identitaria en la proyección de ser salvadoreña o salvadoreño.

\section{Punto de conexión de eso que llamamos cultura}

Hoy por hoy, en cualquier medio se halla un sinnúmero de definiciones de cultura, incluso desde diversos abordajes 0 puntos de vista, pero para el estudio del patrimonio cultural

\footnotetext{
${ }^{1}$ Licenciada en Arqueología y docente Universidad Tecnológica de El Salvador.

${ }^{1}$ Exdirector general de la Unesco.
} 
interesan especialmente las que se plantean desde la antropología (García Cuetos, 2012).

Es así que, antropológicamente, la cultura es entendida como la forma particular de vida de un pueblo o de un período, los modelos o patrones explícitos o implícitos (García Cuetos, 2012). [Ver figura 1.]

Esencialmente, la cultura es un complejo compuesto por conocimientos, creencias, manifestaciones artísticas, costumbres, prácticas, códigos, normas y reglas de la manera de ser, vestimenta, religión, rituales, normas de comportamiento y sistemas de creencias, y cualquier hábito adquirido por los seres humanos como miembros activos de la sociedad (Kottak, 2011; García Cuetos, 2012).

Al mismo tiempo, la cultura es toda la información y las habilidades que poseen los seres humanos y que les permiten integrarse en una sociedad o colectivo (García Cuetos, 2012). Esta premisa marca el punto de partida para el abordaje del patrimonio, por el íntimo vínculo que ambos conceptos presentan, ya que se puede aseverar que este (el patrimonio) es producto de la cultura.

En la figura 1 se puede ver cómo se exterioriza la creación patrimonial. Mapa conceptual de elaboración propia, a partir de lo propuesto por Kottak (2011).

Figura 1. Cualidades específicas asignadas al concepto de cultura. [Elaboración propia con base en el planteamiento de Kottak (2011), complementado con el concepto de Geertz expuesto en Barfield (2000)]

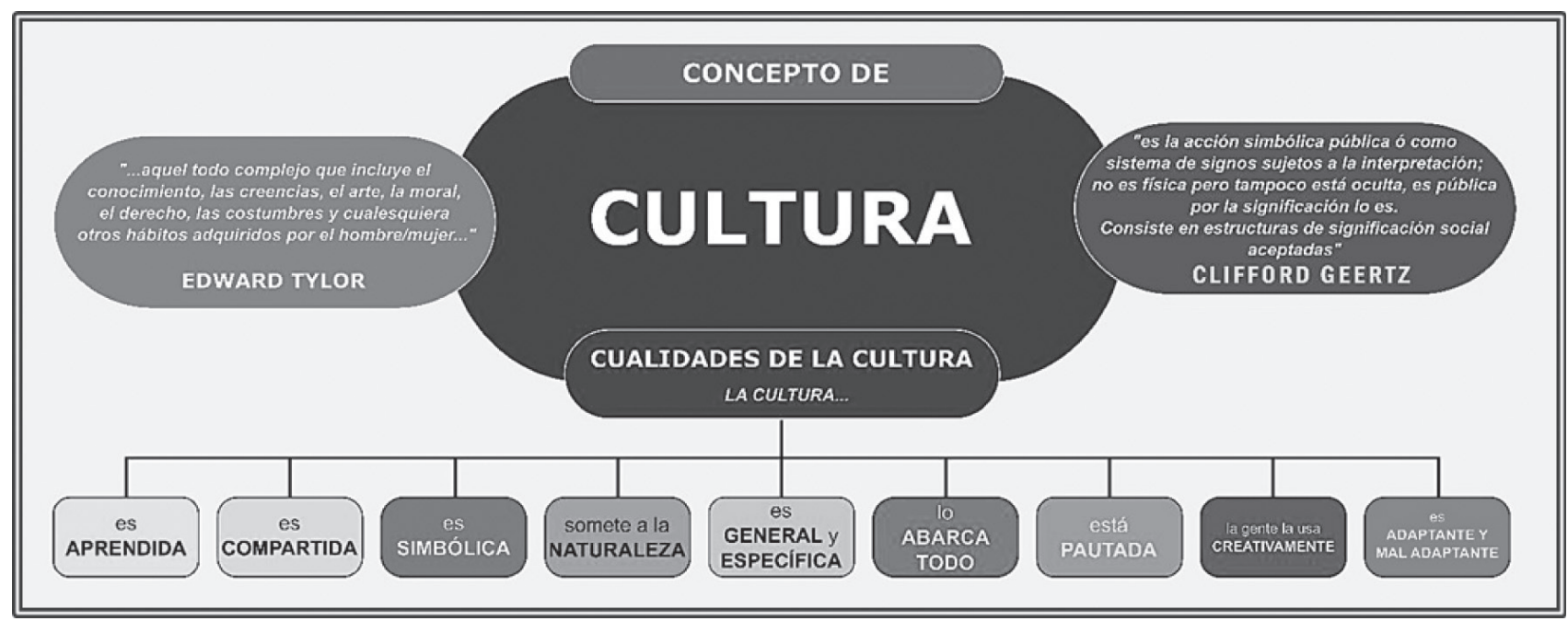

\section{Lo material y lo inmaterial en la representación de la cultura}

De forma genérica se puede razonar que, como parte del complejo cultural, se consideran los utensilios para comer, la forma de vestir, las expresiones arquitectónicas y los implementos utilizados para cazar o para arar la tierra como productos culturales, que son características de sus productores (Centurión Hidalgo, Espinoza Moreno, Poot Matu, \& Cázares Camero, 2003; (Puga, Peschard, \& Castro Martín, 2003).

Desde luego, la cultura abarca una escala extensa y variada de elementos de la vida y de la interacción humana, que representan tanto a la existencia material (artefactos para comer, desarrollo tecnológico, medios de comunicación, etc.) como a la no material (religión, valores, costumbres, ideologías, etc.). (Soliz Tito, Marca Cáceres, \& Navia, 2007.)

En suma, el concepto de cultura se refiere a los valores que los miembros de un grupo social dado comparten, a las normas que acatan y a los bienes materiales que crean y poseen (Puga, Peschard, \& Castro Martín, 2003).

Por consiguiente, se le llama cultura material a todos los objetos tangibles producidos por miembros de una cultura en particular (Barfield, 2000); y varían según la utilidad que tuvieron en su momento, ya sea doméstica o ritual, militar o funeraria, para solventar necesidades de orden económico, técnico, social, político, religioso o estético, lo que es posible 
determinar por las características particulares que cada objeto presente.

Figura 2. El objeto y su función (Cruz, 2001)

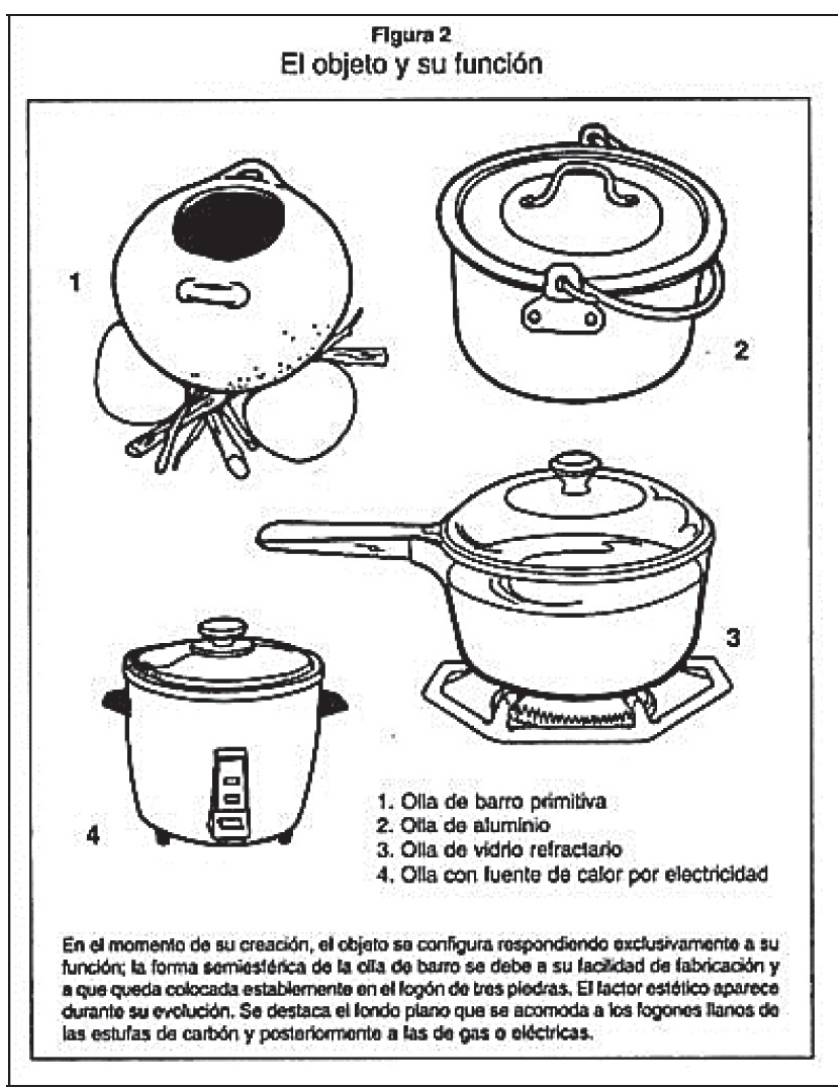

Efectivamente, cada objeto es un documento portador de información o el mensaje producto de una serie de acciones intencionadas, o modos de huellas de la actividad humana, como el uso al que fue destinado, la materia con la que está elaborado, su forma, su decoración, entre muchos otros aspectos (Cruz, 2001).

La cultura material se divide en varias formas fundamentales para fechar la época de sus productores (Sugiura, 2005; Ballart, 2007; Pérex Agorreta, 2013), que a continuación se detallan brevemente.

Artefacto: todo objeto utilitario al servicio y para la comodidad del ser humano (ver figura 2), producto del raciocinio, conocimiento e inventiva humanos, resultado de una tecnología que expresa el nivel de vida, el dominio y manejo de los recursos humanos y materiales de una sociedad (Pérez de Micou, 2006; Renfrew \& Bahn, 2007; Cruz \& Garnica, 2001). Si el artefacto es para la solución de una necesidad, este objetivo lo convierte en utilitario, evidenciando la particularidad de los humanos en los órdenes fisiológicos y sociales como respuesta a las condiciones que motivaron su invención dentro del sistema productivo del momento (Renfrew \& Bahn, 2007).

Ecofacto: elementos de origen vegetal o animal asociados con los artefactos, tales como restos de tallos, hojas, semiIlas, entre otros, ya sean cocidos o no, así como el polen y las partes de animales (Pérez de Micou, 2006; Manzanilla, 2011; Pérex Agorreta, 2013).

Biofacto: capacidad de manipulación genética y domesticación primigenia de algunas plantas y animales, respectivamente, para la satisfacción de necesidades de las sociedades pasadas, como la alimentación y la vestimenta; como ejemplos puntuales, el caso de la milpa: la selección de las semillas, para la próxima cosecha, y la transformación de fibras vegetales en tejidos, para la vestimenta (Simondon, 2007; Ballart, 2007, Telesca, 2010).

Por su parte, la cultura inmaterial es todo aquello ideofacto o simbólico, como las normas, valores, costumbres, tradiciones y los usos que se hace de los artefactos (Bueno, Baba \& Santos, 2003).

Evidentemente, la diferencia entre la cultura material y la inmaterial es imperceptible y en una relación dialéctica, pues en las culturas se da la integración tanto de lo material como de lo inmaterial; no puede existir una sin la otra. Precisamente, la primera se vincula con la adaptabilidad humana y una lógica utilitaria, y segunda se relaciona con el signo y la lógica de su significado (Fernández Poncela, 2000; Bueno, Baba \& Santos, 2003).

\section{El concepto de patrimonio y sus formas}

El término patrimonio proviene del vocablo latino patrimonium o patermonium; de pater, padre, aquello que el padre deja a su hijo. (Korstanje, 2007).

El concepto de patrimonio es moderno y se entiende como el conjunto de bienes heredados de los antepasados; y además, su sentido radica en la propiedad de un individuo o familia. Generalmente se refiere a bienes y costumbres que se transmiten porque se reconoce en ellos un valor, a los que se les atribuye una propiedad colectiva (García Cuetos, 2012). 
A lo largo del tiempo, y especialmente en el siglo XX, el concepto de patrimonio como herencia colectiva evolucionó. Debido a ello es que puede indicarse que, más que un conjunto de bienes, es una construcción social, debido a que es la sociedad misma la que lo reconoce como tal (García Cuetos, 2012). Desde la perspectiva jurídica, tradicionalmente se ha definido como el conjunto de derechos y obligaciones de una persona cuantificables en dinero (Rodríguez, Somarriva Undurraga, \& Vodanovic H., 1998) (Alessandri Rodríguez, Somarriva Undurraga \& Vodanovic, 1998).

De momento, desde la perspectiva de las ciencias económicas y empresariales, se entiende al patrimonio como el

valor residual de los activos del ente económico después de deducir todos los pasivos, y agrupa el conjunto de cuentas que representa el valor remanente de comparar el activo menos el pasivo, producto de los recursos netos del ente económico que han sido suministrados por el propietario de los mismos, ya sea directamente o como consecuencia del giro ordinario de sus negocios (Sinistierra, Polanco y Henao, 2005, pág. 310; citado por Mora Roa, Montes Salazar \& Mejía Soto, 2011).

Mientras que por el turismo es considerado como "la relación entre la materia prima (atractivos turísticos), la planta turística (aparato productivo), la infraestructura (dotación de apoyo al aparato productivo) y la superestructura (subsistema organizacional y recursos humanos disponibles para operar el sistema)" (Quezada Castro, 2010). Es decir, que es entendido aquí como elementos transaccionales, tanto de forma mediata como inmediata, para la obtención de divisas.

Por su parte, desde la Psicología se plantea que el concepto de patrimonio es una convención social, por consiguiente, hay un vínculo afectivo o cierto grado de subjetividades impregnadas por el productor y por el heredero, en pocas palabras, se le tiene aprecio a lo que se ha legado a la siguiente generación, manteniéndose en el tiempo la figura identitaria del que lo legó (Marín Cepeda, 2013).
El patrimonio no está solo constituido por aquellos objetos del pasado que cuentan con un reconocimiento oficial, sino por todo aquello que remite a la propia identidad colectiva como grupo cultural en particular, distinguiéndose así del resto de grupos.

\section{Categorizaciones del patrimonio salvadoreño.}

El patrimonio, en sentido profundo, es el conjunto de objetos materiales e inmateriales, pasados y presentes, que definen a un pueblo: lenguaje, literatura, música, tradiciones, artesanía, bellas artes, danza, gastronomía, indumentaria, manifestaciones religiosas $y$, por supuesto, la historia y sus restos materiales, conformando todo complejo expuesto en el texto de Kottak (2011). A partir de la proposición anterior, se puede establecer que el patrimonio presenta una variedad de categorías, que se muestran en la siguiente figura (ver figura 3).

En primera instancia, obsérvese que el patrimonio se divide en dos grandes vertientes: patrimonio natural y patrimonio cultural, que a su vez, en segunda instancia, se dividen en intangible (inmaterial) y tangible (material) y este en bienes inmuebles y muebles.

El patrimonio natural es entendido como el conjunto de acervos que la naturaleza misma ha producido y que no hay en ellos ninguna intervención humana. A este grupo perteneces los siguientes elementos:

Los monumentos naturales constituidos por formaciones físicas y biológicas, o por grupos de esas formaciones, que tengan un valor universal excepcional desde el punto de vista estético o científico.

Las formaciones geológicas y fisiográficas y las zonas estrictamente delimitadas que constituyan el hábitat de especies, animales y vegetales, amenazadas, que tengan un valor universal excepcional desde el punto de vista estético o científico.

Los lugares naturales, o las zonas naturales estrictamente delimitadas, que tengan un valor universal excepcional desde el punto de vista de la ciencia, de la conservación o de la belleza natural (Unesco, 1972). ${ }^{3}$

\footnotetext{
3 La Convención para la Protección del Patrimonio Mundial Cultural y Natural fue adoptada por la Conferencia General de la Unesco en su XVII reunión realizada en París el 16 de noviembre de 1972. Dicha convención surgió por la necesidad de identificar parte de los bienes inestimables e irremplazables de las naciones. A partir de entonces ha sido ratificada por 191 países, siendo uno de ellos El Salvador, el 8 de octubre de 1991, con un bien patrimonial cultural y tres bienes naturales inscritos.
} 
Figura 3. Categorías del patrimonio. [Infografía elaborada con base en el mapa conceptual sobre el patrimonio propuesto por Hevia et al (2000), citados por Consuegra \& Albayero (2012).]

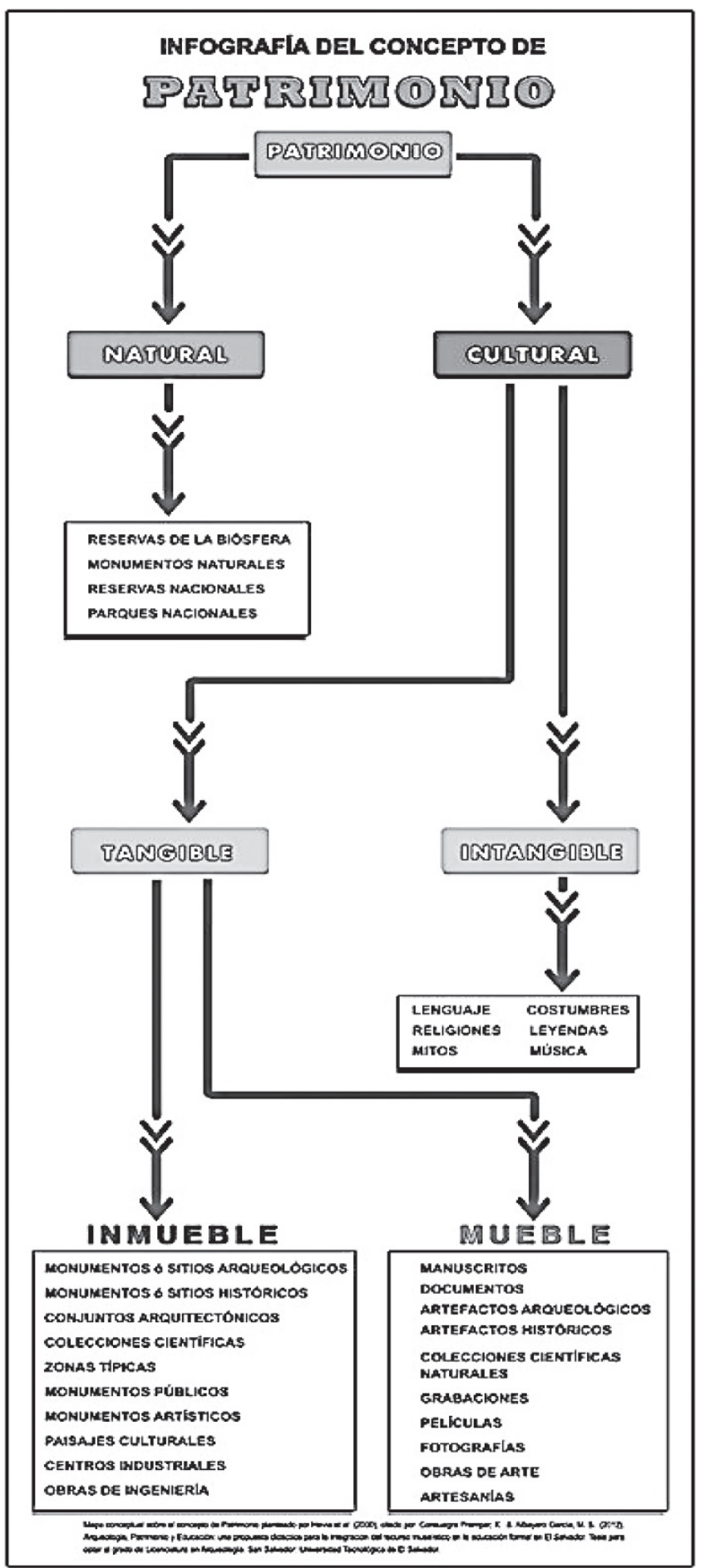

En tal sentido, patrimonio natural de El Salvador se puede presentar en el siguiente orden:

- Reservas de la biosfera

- Monumentos naturales

- Reservas nacionales

- Parques nacionales

- Sitios ramsar ${ }^{4}$

De acuerdo con la Convención para la Salvaguardia del Patrimonio Cultural Inmaterial (Unesco, 2016), este patrimonio se manifiesta, en particular, en los ámbitos siguientes:

a. Tradiciones y expresiones orales, incluido el idioma como vehículo del patrimonio cultural inmaterial.

b. Artes del espectáculo.

c. Usos sociales, rituales y actos festivos.

d. Conocimientos y usos relacionados con la naturaleza y el universo.

e. Técnicas artesanales tradicionales.

f. Ideofactos.

Entre otros elementos culturales. Con base en lo anterior, patrimonio cultural de El Salvador se puede presentar en el orden que se muestra a continuación:

- Lenguaje

- Leyendas

- Costumbres

- Mitos

- Religiones

- Música

Particularmente, se puede plantear que el patrimonio cultural tangible (material) es la expresión de la cultura a través de grandes realizaciones materiales o como una proeza técnica, y está constituido tanto por bienes muebles como por inmuebles (Galaz-Mandakovic Fernández, 2011). Entre ellos cabe apuntar, además, las obras de arte, libros manuscritos, documentos, grabaciones, fotografías, películas, documentos audiovisuales, artesanías, entre muchos otros objetos (Galaz-Mandakovic Fernández, 2011) de todas las categorías. Este patrimonio es el más abundante en comparación con las demás categorías. 4 "Convención relativa a los humedales de importancia internacional, especialmente como hábitat de aves acuáticas. Es un tratado intergubernamental firmado en
la ciudad de Ramsar (Irán) en 1971, en el que la Unesco es el organismo depositario de la Convención" (Fundación Hogares Juveniles Campesinos, 2006, p. 82). 
Consecutivamente, se entiende que el patrimonio cultural inmueble son todas aquellas obras o producciones humanas que, en efecto, no se pueden trasladar de un lagar a otro debido a que, por lo general, son estructuras o porque presentan una fuerte relación con el terrero donde se encuentran ubicadas (Galaz-Mandakovic Fernández, 2011).

A continuación, se proponen los elementos para El Salvador en el siguiente orden:

\begin{tabular}{|lc|}
\hline \hline & Patrimonio cultural tangible \\
\hline Mueble & Inmueble \\
* Documentos & $\S$ Monumentos o sitios \\
* Artefactos & arqueológicos \\
históricos & $\S$ Monumentos o \\
* Colecciones & sitios históricos \\
científicas & $\S$ Conjuntos \\
* Naturales & arquitectónicos \\
* Grabaciones & $\S$ Colecciones \\
* Películas & científicas \\
* Fotografías & $\S$ Zonas típicas \\
* Obras de arte & $\S$ Monumentos públicos \\
* Artesanía & $\S$ Monumentos artísticos \\
& $\S$ Paisajes culturales \\
& $\S$ Centros industriales y \\
& obras de ingeniería \\
& (patrimonio industrial) \\
\hline
\end{tabular}

Adicionalmente, pero siempre en el parámetro del patrimonio cultural, se exaltan dos tipos de patrimonio por sus características notables. En primer lugar, se encuentra el patrimonio etnológico, que al igual que el natural y el cultural son una construcción social es producida históricamente, implicando una selección de la realidad de un determinado momento de la vida diaria de una comunidad muy singular.

Desde el punto de vista antropológico, la singularidad de dicho grupo se refiere a las formas de vida y los sistemas ideológicos y de sus creencias en toda su complejidad pasada y presente, siendo la parte medular de este patrimonio el conocimiento a partir del testimonio de sus herederos. En consecuencia, la importancia contundente surge de la investigación, conservación, difusión y restitución como tratamiento antropológico del patrimonio de forma integral por parte de los estudiosos de la cultura (Moure Romanillo \& Bar Cendón, 1995).

En segundo lugar, y no menos importante, por encontrarse vinculado estrechamente con el patrimonio etnológico, se halla el patrimonio viviente. Este patrimonio se refiere al hecho de que, las personas están dotadas de un espíritu creador, que es su capacidad distintiva, la que los diferencia de los otros organismos vivos. Ese es el milagro de la vida humana. Por lo que es importante destacar que las distintas expresiones, manifestaciones y creaciones, como la música, la danza, la lengua, los ritos no existen físicamente y son los elementos intangibles tradicionales utilizados por quienes protegen y preservan el patrimonio cultural material, considerándose en virtud las técnicas para reparar instrumentos musicales tradicionales, o para trabajar sillares en monumentos antiguos, o para consolidar y restaurar techos con métodos y utensilios tradicionales, entre otros. Por ello, la Unesco considera a dichas personas como "Tesoros Humanos Vivientes", puesto que encarnan y poseen en su grado más alto las habilidades y técnicas necesarias para la producción de los aspectos seleccionados de la vida cultural de un pueblo y para la existencia continua de su patrimonio cultural material (Albayero, 2016).

Figura 4. Abordaje del concepto desde diferentes disciplinas del conocimiento. Propuesto por Llull Peñalba (2005), citado por Consuegra \& Albayero (2012), citado por Consuegra \& Albayero (2012).




En tercer lugar, y también en el mismo nivel de importancia que todas las categorías del patrimonio, se encuentra el patrimonio mundial, forjado como un patrimonio con valor universal, tanto en la vertiente natural como en la cultural. Los sitios con esta categoría son los lugares que no solamente les pertenecen a los territorios en los que se sitúan, sino que a todos los pueblos del planeta; y el principal criterio que deben cumplir los territorios y sitios es el de Valor Universal Excepcional desde el punto de vista de la historia, del arte o de la ciencia, tanto para la vertiente natural como para la cultural.

La salvaguardia y la protección permanente de estos lugares excepcionales es de vital importancia para el conjunto de la comunidad internacional, por ello se ha creado un comité, que es el que define los criterios de inscripción de los bienes en la Lista del Patrimonio Mundial (Albayero, 2016).

Finalmente, y no menos importante, el patrimonio nacional, concebido como el conjunto de los valores asignados para un momento determinados de los recursos disponibles de un país, que se utilizan para la vida económica y la integración de las vertientes del patrimonio natural y el patrimonio cultural, de allí la importancia de su carácter jurídico.

Jurídicamente, el patrimonio se encuentra integrado por los siguientes cimientos (Querol, 2010):

a. Su composición como conjunto unitario de derechos y de obligaciones: entendida como la regulación mediante la Ley Especial de Protección al Patrimonio Cultural de El Salvador, lo que se puede observar un poco más detallado en la figura 4, el abordaje del concepto desde diferentes disciplinas del conocimiento.

b. Su significación económica y pecuniaria, ya que solo las relaciones jurídicas de carácter pecuniario (derechos reales, derechos de crédito), forman el contenido del patrimonio. En el patrimonio nacional, su valor es inestimable e irremplazable, lo que quiere decir que si desaparece o sufre daños representaría una pérdida irreparable, ya que, aunque se diga que es para el disfrute del país, también su función es la de interpretar al pasado de forma crítica, para el desarrollo de la sociedad salvadoreña.

c. Su atribución a un titular como centro de sus relaciones jurídicas. En el caso particular del patrimonio nacional, en su conjunto de natural y cultural, los titulares en nombre del Estado son, respectivamente, los del Ministerio de Medio Ambiente y Recursos Naturales y de la Secretaría de Cultura de la Presidencia los que deben garantizar la protección y salvaguarda del patrimonio per se.

\section{El patrimonio como fuente de las identidades}

Los países tienen leyes para calificar como patrimonio nacional, bajo ciertas condiciones, a determinados objetos y no a otros, que se hacen extensivas, no solo a asuntos del pasado que tienen que ver con los muertos, sino también tanto con cuestiones relacionadas con los vivos como con las personas a quienes se les reconoce su calidad de ser patrimonio nacional.

El patrimonio, integralmente, es un patrimonio público recibido del pasado, que se considera en el presente como colectivo; y los límites deben ser interpretados por la comunidad por lo menos para hacer distinción de aquello considerado como patrimonio privado (Pérez García, Hijar Serrano, Gallegos Téllez Rojo, Balderas, \& Flores Padilla, 2008).

Si el patrimonio, en su misma definición, aparece como una posesión heredada por sus predecesores y de carácter colectivo, y si sus hipotéticos propietarios (sucesores) no son capaces de identificarlo como propio, ocurre algo inusual que merece ser analizado de la siguiente manera (texto tomado de Albayero, 2016):

Que determinados grupos sociales estén interesados en ocultar esa propiedad de modo que sus legítimos dueños no fueran capaces de identificarla como propia (fenómeno de alienación).

Que haya una discrepancia entre el sentir de la comunidad y lo que los políticos definen como patrimonio cultural mediante las leyes. Es probable que se deba a que los políticos interpretan mal o que no tengan la capacitación para desempeñar la función de portavoces y no logren comprender el significado colectivo del bien cultural; y por eso lo desechen.

Que el contenido de los bienes culturales colectivos no tenga o tenga muy poco que ver con lo que los ciudadanos en su conjunto sienten como suyo; que obedeciera a la presión de ciertos grupos de opinión sobre los políticos que 
estarían induciéndolos a definir ese patrimonio en función de sus propios intereses.

Que el sistema educativo no esté desempeñando su labor de transmisora de la cultura, y por ende del patrimonio, de forma sistemática y técnica en la formación académica de sus legítimos dueños.

Que para las municipalidades no sea de su interés político e ideológico propiciar programas que legitimen la identidad local.

Que los medios de comunicación masivos, tanto televisivos como escritos, presenten información sobre el patrimonio cultural en forma parcializada y desacertada por desconocimiento intencional o no.

De aquí surge la inquietud de entonces ¿cómo se sabe cuál bien es patrimonial cuál no? Para que obtenga este carácter patrimonial debe ser activado socialmente por el consenso de la sociedad en su conjunto o de las instituciones locales.

Como posible solución de qué es y qué no es patrimonial. García Canclini (1999) apunta que son las clases dominantes, en la construcción y apropiación del patrimonio, las que establecen una jerarquía de los capitales culturales. Por ejemplo, vale más el arte que las artesanías; la medicina científica que la popular; la cultura escrita que la oral.

De tal manera que el patrimonio se vuelve un espacio de contienda económica, política y simbólica, en donde se circunscribe la acción de los siguientes tres agentes que deciden la patrimonialización de los bienes identitarios de un lugar, como se explica seguidamente.

El sector privado. Se basa en el acaparamiento económico, reproducción de la fuerza de trabajo y muy frecuentemente explota el patrimonio en forma indiscriminada.

El Estado. Presenta una actuación contradictoria frente al patrimonio. Por un lado, lo valora y promueve como elemento integrador de la nacionalidad, y por otro, al mismo tiempo tiende a trastocar las realidades locales en idealizaciones político culturales, en símbolos de una identidad nacional en que se disuelven las particularidades (homogenización cultural) y los conflictos.

Los movimientos sociales. Surgen a raíz de la expansión demográfica, la urbanización descontrolada y la depredación ecológica, para recuperar barrios y edificios, o por mantener habitable el espacio urbano, como es el caso de los centros históricos de las principales ciudades de un país. Es así que las demandas en el uso del patrimonio tienen la forma que toma la interacción entre estos sectores en cada período, según lo argumentado por García Canclini (1999) al respecto.

Al igual que ocurre con todas las manifestaciones socioculturales, la identidad cambia y evoluciona constantemente, y cada nueva generación tiene la posibilidad de recupera y enriquecer aquellos elementos culturales que se ven amenazados por el fenómeno de la globalización de la cultura, y, además, la identidad guarda relación directa con el patrimonio, cuya existencia permanece arraigada en la mentalidad del pueblo, por lo general expresadas en la ideología de clases, pues ya se dicho en este documento que son estas las que determinan qué hay que patrimonializar (Reynosa Navarro, 2015).

Pero aun a pesar de este pronóstico, la cultura es la memoria social expresada en el patrimonio en sus dos principales vertientes. Justamente, el patrimonio es la expresión máxima de la cultura salvadoreña y es la condición cultural que permite identificarse, caracterizarse y diferenciarse de otras culturas. Permite percibir quiénes y cómo son los salvadoreños y cuál es papel activo de cada integrante en el desarrollo cultural comunitario, implicándose el entorno, la historia y la voluntad creativa de la persona.

La identidad cultural promueve y conserva la historia y el patrimonio cultural, puesto que se actualiza constantemente, ya que el ser humano asiduamente está creando obras trascendentales. Tiene, además, una relación sociocultural decisiva dentro del proceso de desarrollo social.

La identidad florece cuando cada grupo humano se autodefine $y$, a la vez, es reconocido como tal por los demás grupos. La producción de lo material y lo inmaterial da cuenta de la herencia de los pueblos. Por tanto, la identidad es cultura, $y$, aunque no llega a todos por igual ni es interpretada de la misma manera por todos, merece empoderamiento social y difusión constante.

Por ello es preciso aseverar que "la identidad exige su esclarecimiento, ya sea de sí mismo o de un ser -otroque la formule; es un acto de conciencia, pero que expresa una realidad objetiva y subjetiva de carácter histórico más allá de la voluntad del enunciador" (Reynosa Navarro, 2015). 
Con la incursión y los impactos de la globalización de forma acelerada, en donde se ha pretendido una uniformidad cultural, a pesar de ello, la pluralidad cultural continua presente reclamando atención y reconocimiento.

Las identidades no se presentan como losetas gigantescas, estas son cambiantes, puesto que el ser humano no asume por mandato divino una única identidad, sino que múltiples; los sujetos tienen la capacidad de discriminarlas, seleccionarlas y adscribirse según las circunstancias en las que aparezcan, ya que son imaginarios pactados y cargados de simbolismos que influyen en la práctica sociocultural. (Valenzuela Arce, 2015).

En la construcción de las identidades, el conflicto y la contradicción son algo inevitable, en el entendido de que estas son dimensiones de los sujetos sociales, por lo que hay presente un discurso oculto de los grupos dominantes sobre los dominados (Martínez, 2004), tal como plantea García Canclini (1999): que una cosa es mejor que otra.

En este sentido, la salvadoreñidad no es ajena a estos debates y discusiones, debido a la historia de negación de las minorías étnicas en El Salvador; por la identidad construida por la cultura dominante de una elite económica que, sin temor a equivocación, ve al patrimonio en sus vertientes como fuente de mercancía y no como elemento que caracteriza a cada habitante del país.

\section{Consideraciones finales}

El concepto integral de patrimonio tiene como dimensión la globalidad del territorio y sus habitantes; como objetivo último, la calidad de vida como consecuencia de un desarrollo económico y social sostenible; su metodología es la gestión integral de los recursos patrimoniales a partir de estrategias territoriales.

El patrimonio es el testimonio tangible e intangible de las expresiones de la cultura de un pueblo, ya que son la expresión colectiva de las reivindicaciones y nociones propias de cada grupo humano, en un proceso de elaboración y reelaboración.

El patrimonio de forma integral refleja los sentimientos de pertenencia y arraigo los bienes culturales, que requieren ser protegidos desde una visión completa, dinámica y sistemática, ya que estos no solo son una construcción social material, sino que son una constante abstracción de la creatividad de sus depositarios y de los herederos que le dan continuidad desde el pasado, en el presente con la mirada en el futuro.

Y, por último, el Estado, en su calidad de titular, junto con cada uno de los habitantes del país son los que deben garantizar el cuido y protección del patrimonio en sus dos vertientes principales para el disfrute y aprendizaje crítico de las futuras generaciones.

\section{Referencias}

Albayero, S. (2016). Seminario: Patrimonio Cultural de El Salvador. San Salvador: Utec. Recuperado de https:// issuu.com/sofiaalbayero/docs/material_seminario_ patrimonio_cultu

Alessandri Rodríguez, A., \& Somarriva Undurraga, M. (1998). Tratado de derecho civil: partes preliminar y general. Santiago: Editorial Jurídica de Chile.

Ballart, J. (2007). El patrimonio histórico y arqueológico, valor y uso. Barcelona: Editorial Ariel.

Barfield, T. (2000). Diccionario de antropología. México: Siglo XXI editores.

Bueno, C., \& Baba, M. \&. (2003). Nuevas tecnologías y cultura. Barcelona: Anthropos Editorial.

Centurión Hidalgo, D.; Espinoza Moreno, J.; Poot Matu, E., \& Cázares Camero, J. (2003). "Cultura alimentaria Tradicional de la región Sierra de Tabasco". Villahermosa, Tabasco: Universidad Juárez Autónoma de Tabasco.

Consuegra, K., \& Albayero, M. (2012). "Arqueología, patrimonio y educación: una propuesta didáctica para la integración del recurso museístico en la educación formal en El Salvador". San Salvador: Utec.

Cruz, J. \&. (2001). Principios de ergonomía. Santafé de Bogotá: Universidad de Bogotá Jorge Tadeo Lozano.

Fernández Poncela, A. (2000). Mujeres, revolución y cambio cultural: transformaciones sociales "versus" modelos culturales persistentes. Barcelona: Anthropos Editorial.

Fundación Hogares Juveniles Campesinos (2006). Manual abecedario ecológico: la más completa guía de términos ambientales. Bogotá: Editorial San Pablo.

Galaz-Mandakovic Fernández, D. (2011). Reivindicación del Patrimonio Tangible de Tocopilla. Chile: Ediciones Retruecanosinversos.

García Cuetos, M. (2012). El patrimonio cultural: conceptos básicos. Zaragoza: Prensas de la Universidad de Zaragoza. 
Korstanje, M. (2007). Tratado turístico. España: Enciclopedia y Biblioteca Virtual de las Ciencias Sociales, Económicas y Jurídicas, Facultad de Derecho de la Universidad de Málaga. Recuperado de www.eumed. net/libros/2007c/321/

Kottak, C. (2011). Antropología Cultural. México, D. F.: McGraw-Hill Companies.

Manzanilla, L. (2011). "Las ciencias y la arqueología". Ciencias 104, Octubre-Diciembre, 40-51. http:// www.revistacienciasunam.com/es/112-rev https:// issuu.com/sofiaalbayero/docs/material_seminario_ patrimonio_cultu

Marín Cepeda, S. (2013). “Una nueva geografía patrimonial; la diversidad, la psicología del patrimonio y la educación artística". València: Institut Universitari de Creativitat i Innovacions Educativ. Recuperado de https://ojs.uv.es/ index.php/eari/article/view/2671/2292

Martínez, D. (2004). "Identidades culturales y relaciones de poder en las prácticas educativas: construcción de subjetividad y malestar docente". Buenos Aires: Centro de Publicaciones Educativas y Material Didáctico.

Mora Roa, G.M. (2011). "Contabilidad Internacional y Responsabilidad Social de las Organizaciones". España: Grupo de Investigación eumednet. Recuperado de http://www.eumed.net/libros-gratis/2011b/949/ Concepto\%20de\%20p

Moure Romanillo, A. \&. (1995). "De la Montaña a Cantabria: la construcción de una comunidad autónoma". Santander: Universidad de Cantabria.

Pérex Agorreta, M. (2013). Métodos y Técnicas de Investigación Histórica I. Costa Rica: Editorial Uned.

Pérex Agorreta, M. (2013). Métodos y Técnicas de Investigación Histórica I. Costa Rica: Editorial Uned.

Pérez de Micou, C. (2006). "El modo de hacer las cosas. Artefactos y ecofactos en Arqueología". Buenos Aires: Universidad de Buenos Aires.

Pérez García, M.; Hijar Serrano, A.; Gallegos Téllez Rojo, J.R.; Balderas, E., \& Flores Padilla, G. (2008). Patrimonio Documental: fondos institucionales. México, D. F.: Instituto Nacional de Bellas Artes y Literatura.

Puga, C.; Peschard, J., \& Castro Martín, T. (2003). Hacia la sociología. Naucalpan, Estado de México: Pearson Educación.

Quezada Castro, R. (2010). Elementos de Turismo. Teoría, Clasificación y Actividad. San José, Costa Rica: Euned.
Renfrew, C. \&. (2007). Arqueología: teorías, métodos y práctica. Madrid: Ediciones Akal.

Reynosa Navarro, E. (2015). Patrimonio cultural e identidad. Argumentos teóricos. Perú: GRIN verlag GmbH. ISBN 978-3-668-06494-2.

Rodríguez, A.; Somarriva Undurraga, M., \& Vodanovic, H.A. (1998). Tratado de derecho civil: partes preliminar y general. Santiago: Editorial Jurídica de Chile.

Sánchez González, M. (2010). Técnicas docentes y sistemas de evaluación en educación superior. Madrid: Narcea.

Simondon, G. (2007). El modo de existencia de los objetos técnicos. Buenos Aires: Prometeo Libros.

Soliz Tito, L.; Marca Cáceres, J., \& Navia, N. (2007). "Relaciones interculturales, sociopolíticas y productivas en municipios de Santa Cruz y Cochabamba". La Paz: Universidad para la Investigación Estratégica en Bolivia.

Sugiera, Y. (2005). "Y atrás quedó la ciudad de los dioses: historia de los asentamientos en el Valle de Toluca". México, D.F.: Universidad Nacional Autónoma de México, Instituto de Investigaciones Antropológicas.

Telesca, I. (2010). Historia del Paraguay. Asunción: Ediciones Taurus.

Unesco (1972). "Convención sobre la protección del patrimonio mundial, cultural y natural". París: Organización de las Naciones Unidas para la Educación, la ciencia y la cultura. Recuperado de: http://whc. unesco.org/archiv e/conv ention-es.pdf

Unesco (2016). "Convención para la Salvaguardia del Patrimonio Cultural Inmaterial". París: Organización de las Naciones Unidas para la Educación, la ciencia y la cultura. Recuperado de http://www.unesco.org/ culture/ich/es/convenci\%C3\%B3n

Valenzuela Arce, J. (2015). “Decadencia y auge de las identidades. Cultura nacional, identidad cultural y modernización". Baja California: El Colegio de la Frontera Norte.

Velasco Quintana, P. p. (2016). “El turismo cultural, ámbito privilegiado para la protección del patrimonio cultural inmaterial. Definición legislativa y límites". Telos 104. Revista de Pensamiento sobre Comunicación, Tecnología y Sociedad. Junio-Septiembre 2016. Fundación Telefónica, pp. 98-108. 